\title{
Should I stay or should I go? COPD and air travel
}

\author{
Begum Ergan (1) ${ }^{1}$, Metin Akgun², Angela Maria Grazia Pacilli ${ }^{3}$ and \\ Stefano Nava ${ }^{3}$
}

Affiliations: ${ }^{1}$ Dept of Pulmonary and Critical Care, School of Medicine, Dokuz Eylul University, Izmir, Turkey. ${ }^{2}$ Dept of Pulmonary Diseases, School of Medicine, Ataturk University, Erzurum, Turkey. ${ }^{3}$ Dept of Clinical, Integrated and Experimental Medicine (DIMES), Respiratory and Critical Care Unit, S. Orsola-Malpighi Hospital, Alma Mater University, Bologna, Italy.

Correspondence: Begum Ergan, Dept of Pulmonary and Critical Care, School of Medicine, Dokuz Eylul University, Izmir, 35340, Turkey. E-mail: begumerganahotmail.com

@ERSpublications

COPD patients should be informed about the "fitness to fly" concept and patients with moderate-tosevere disease need to be assessed with clinical and functional parameters for possible risk factors for in-flight hypoxaemia before flying http://ow.ly/Yd4A30k41Hq

Cite this article as: Ergan B, Akgun M, Pacilli AMG, et al. Should I stay or should I go? COPD and air travel. Eur Respir Rev 2018; 27: 180030 [https://doi.org/10.1183/16000617.0030-2018].

ABSTRACT Chronic obstructive pulmonary disease (COPD) is a challenging respiratory problem throughout the world. Although survival is prolonged with new therapies and better management, the magnitude of the burden resulting from moderate-to-severe disease is increasing. One of the major aims of the disease management is to try to break the vicious cycle of patients being homebound and to promote an active lifestyle. A fundamental component of active daily life is, of course, travelling. Today, the world is getting smaller with the option of travelling by air. Air travel is usually the most preferred choice as it is easy, time saving, and relatively inexpensive. Although it is a safe choice for many passengers, the environment inside the aeroplane may sometimes have adverse effects on health. Hypobaric hypoxaemia due to cabin altitude may cause health risks in COPD patients who have limited cardiopulmonary reserve. Addressing the potential risks of air travel, promoting proactive strategies including pre-flight assessment, and education of COPD patients about the "fitness to fly" concept are essential. Thus, in this narrative review, we evaluated the current evidence for potential risks of air travel in COPD and tried to give a perspective for how to plan safe air travel for COPD patients.

\section{Introduction}

Chronic obstructive pulmonary disease (COPD) is a preventable disease that is characterised by airflow limitation. The prevalence and burden of COPD are projected to increase over the coming decades due to an ageing world population and, according to World Health Organization estimates, currently 65 million people have moderate-to-severe COPD [1]. Recent data confirm this projection by a fall of $23 \%$ in age-standardised death rates and prolonged life expectancy in COPD [2]. Thus, the number of patients with severe disease and chronic respiratory failure will increase in the near future.

In contrast to historic beliefs, COPD is now considered a treatable disease [3]. Our perspective about the disease and the management algorithms has changed markedly. We now aim to optimise our patient's wellbeing both physically and psychologically and increase their quality of life as much as possible. Individualised medical treatments, effective management of exacerbations and comorbidities, encouragement of physical activity and rehabilitation are the cornerstones of COPD management.

Provenance: Submitted article, peer reviewed.

Received: March 202018 | Accepted after revision: April 302018

Copyright OERS 2018. ERR articles are open access and distributed under the terms of the Creative Commons Attribution Non-Commercial Licence 4.0. 
Developments in technology and the wide availability of supportive treatments such as rehabilitation, long-term oxygen therapy, ambulatory oxygen support and noninvasive ventilation helped patients to become more physically active and mobile. Instead of being homebound, most of the COPD patients usually continue their daily life, such as going out, taking part in sports, and of course travelling.

Within years, air travel became the first choice mode of travel. It is fast, practical and becoming less expensive. According to World Bank data, 3.696 billion persons used commercial air travel worldwide in 2016 (figure 1) [4].

Due to the ageing population, the number of passengers with pre-existing medical conditions, which are mainly cardiovascular, and chronic airway diseases including COPD, are expected to increase $[5,6]$. Therefore, healthcare providers need to identify and minimise the risks for individuals who have a high risk of air travel with reduced physiological reserves. It was previously reported that respiratory medical emergencies represent $7-11 \%$ of all in-flight incidents and COPD was the main disease for pre-flight medical screening [5]. In this narrative review, we will provide an overview of literature data up to 2018 about travelling safely with COPD and try to answer the patient's question of "should I stay or should I go?"

A comprehensive background literature search has been carried out in PubMed and other search engines with the keywords "air travel", "flight", "patient", "fitness to fly", "chronic obstructive pulmonary disease" and "oxygen supplementation". Relevant articles were chosen and reference lists were checked for publications related to the subject. In addition, patient-centred information websites prepared by different organisations were screened and the content was assessed.

\section{General risk of flying}

Modern commercial aircrafts are safe and comfortable. Aircrafts for long-haul flights can cover more than 5000 kilometres and fly for up to $14 \mathrm{~h}$ without stopping. To fly as economically as possible over long distances, the general rule is to use wide-body aircrafts with a large number of seats. Contrary to popular belief, the aircraft cabin is not pressurised to ground level equivalent. For mechanical and economic reasons, it is practically impossible to maintain a ground level equivalent pressure at high cruising altitudes [7-10]. Thus, aircraft cabins are designed with pressure differentials, which represent the compromise between the physiological ideal and the optimal technological design. Regulatory governmental agencies require aircraft cabins be pressurised to simulate an altitude of $2438 \mathrm{~m} \mathrm{(8000} \mathrm{ft} \mathrm{cabin} \mathrm{altitude)} \mathrm{and} \mathrm{allow} \mathrm{only} \mathrm{short}$ diversions to a cabin altitude of $3048 \mathrm{~m}(10000 \mathrm{ft})$ for safety reasons [8]. However, cabin altitude may vary to an extent and it was reported that cabin altitude $>8000 \mathrm{ft}$ was observed in up to $10 \%$ of flights [9-12]. It may also sometimes be necessary to have higher altitudes with lower cabin pressures especially towards the end of intercontinental flights as the aircraft gets lighter because of the fuel used [13]. The threshold of altitude-induced hypoxaemia is generally considered to be $1000 \mathrm{~m}(3300 \mathrm{ft})$ and the selection of $2438 \mathrm{~m}$

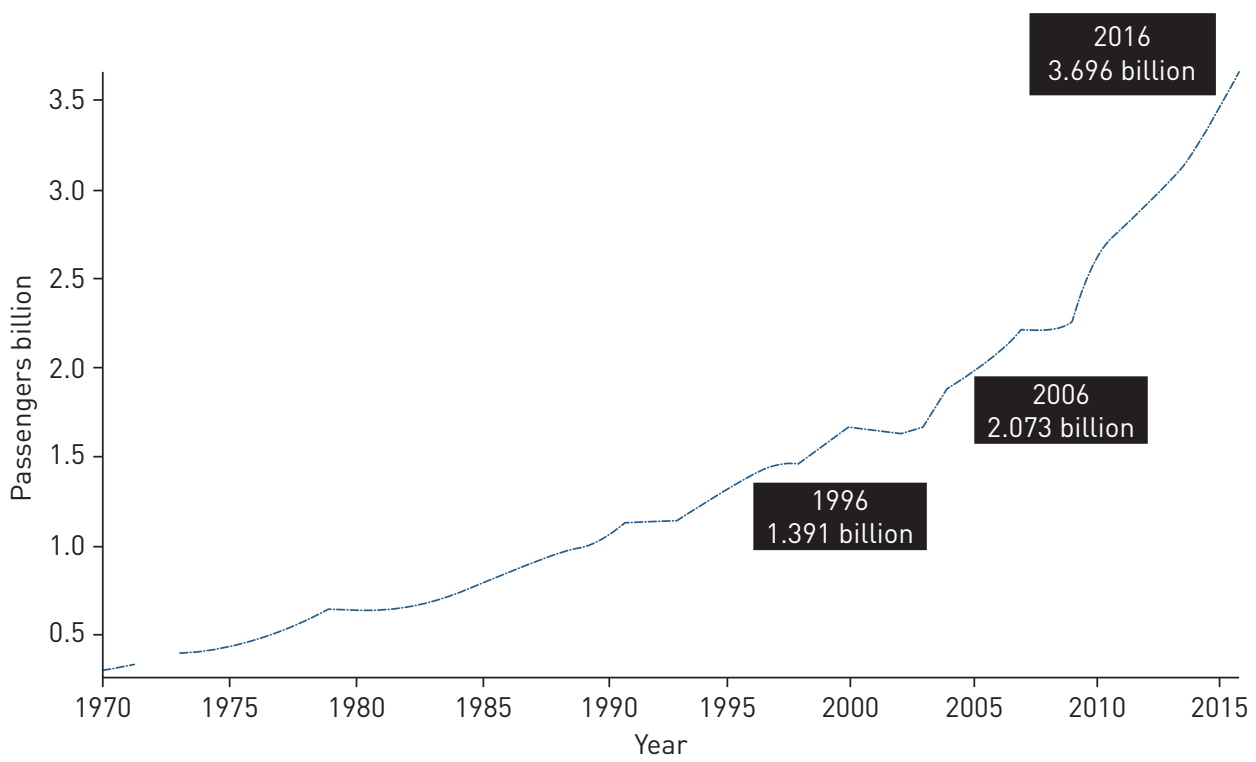

FIGURE 1 World Bank Data for numbers of passengers who travelled by air between 1970 and 2016 . Reproduced from [4] with permission. 
was based on the oxyhaemoglobin dissociation curve which shows that up to that level the arterial oxygen saturation $\left(\mathrm{SaO}_{2}\right)$ normally remains above $90 \%$ in the average healthy individual $[9,10]$.

The risk of flying is relatively low for a healthy individual. But one has to bear in mind that the initial effects of unrecognised hypoxaemia are usually insidious, with reduced cognitive function and other mild symptoms occurring some time before significant, more readily recognised clinical events, such as chest pain, shortness of breath, seizures and loss of consciousness [9]. A medical emergency occurs in 1 out of every 604 flights and per 30000 passengers $[14,15]$. Respiratory illnesses comprise $\sim 12 \%$ of all in-flight emergencies; other emergencies include syncope (37.4\%), cardiac symptoms (7.7\%), stroke (2\%) and cardiac arrest (0.3\%) [14]. Most of those in-flight emergencies, around 65\%, are due to a pre-existing medical condition [16]. The rate of in-flight death is $0.3 \%$ of in-flight emergencies and one per 3 to 10 million passengers $[14,15,17]$. Diversion due to a medical emergency is $\sim 7-11 \%$ of total in-flight medical events and respiratory symptoms were reported as the third most frequent cause of diversion [14, 18, 19]. Flight diversions due to medical emergencies carry a significant financial and legal cost. Ground-based medical services including telemedicine are considered to be helpful for obtaining valuable medical advice, making the decision of diversion, minimising the risk for the sick passenger, and decreasing the possibility of inconvenience for other passengers [8]. Ideally, implementing a proactive prevention strategy including pre-flight screening for these groups of passengers may reduce in-flight adverse events and therefore diversions due to a medical problem. The medical risk of flying does not stop upon arrival at the destination. Another problem that is usually unnoticed is the need for healthcare utilisation after flying. It was observed that unscheduled healthcare use in patients with respiratory problems is up to $20 \%$ within the first month after a flight [20].

\section{The environment inside the aircraft: alterations in gas exchange and haemodynamics at high altitude}

The primary difference between the aircraft cabin and ground environment is the atmospheric pressure and in most passenger aircrafts the cabin pressure at cruising level corresponds to an ambient altitude of 1500-2450 m (5000-8000 ft) [10]. This specific cabin pressure causes hypobaric hypoxaemia. As a result of low barometric pressure, the inspired oxygen tension decreases in turn leading to a fall in alveolar oxygen tension and consequently arterial oxygen tension $\left(\mathrm{PaO}_{2}\right)$ [21-23]. While the barometric pressure at sea level is $760 \mathrm{mmHg}(101 \mathrm{kPa})$, which corresponds to a $\mathrm{PaO}_{2}$ of $96-98 \mathrm{mmHg}(13 \mathrm{kPa})$, the barometric pressure at $8000 \mathrm{ft}$ is about $565 \mathrm{mmHg}(75 \mathrm{kPa})$ resulting in a $\mathrm{PaO}_{2}$ level of $55 \mathrm{mmHg}(7.3 \mathrm{kPa})$ $(750 \mathrm{mmHg}=100 \mathrm{kPa} ; 100 \mathrm{mmHg}=13.3 \mathrm{kPa})$. In healthy individuals, $\mathrm{PaO}_{2}$ levels are between 53 and $75 \mathrm{mmHg}(7-10 \mathrm{kPa})$ and this causes a 3-4\% decrease in $\mathrm{SaO}_{2}$ which is usually $>90 \%$ (figure 2) [24-26]. This results in tissue hypoxia (hypobaric hypoxia) from inspiring oxygen-poor air, which causes compensatory physiological changes at high altitude both at rest and during exercise [19, 21, 27]. Compensatory mechanisms for hypoxaemia are increased minute ventilation, increased heart rate and, therefore, cardiac output for maintaining oxygen delivery [21, 25, 27, 28]. Pulmonary vasoconstriction redistributes pulmonary blood flow to the apical regions of the lung to reduce ventilation-perfusion

FIGURE 2 Oxyhaemoglobin dissociation curve for healthy individuals and patients with chronic obstructive pulmonary disease (COPD) at high altitude. $\mathrm{PO}_{2}$ : oxygen tension. Reproduced from [26] with permission.

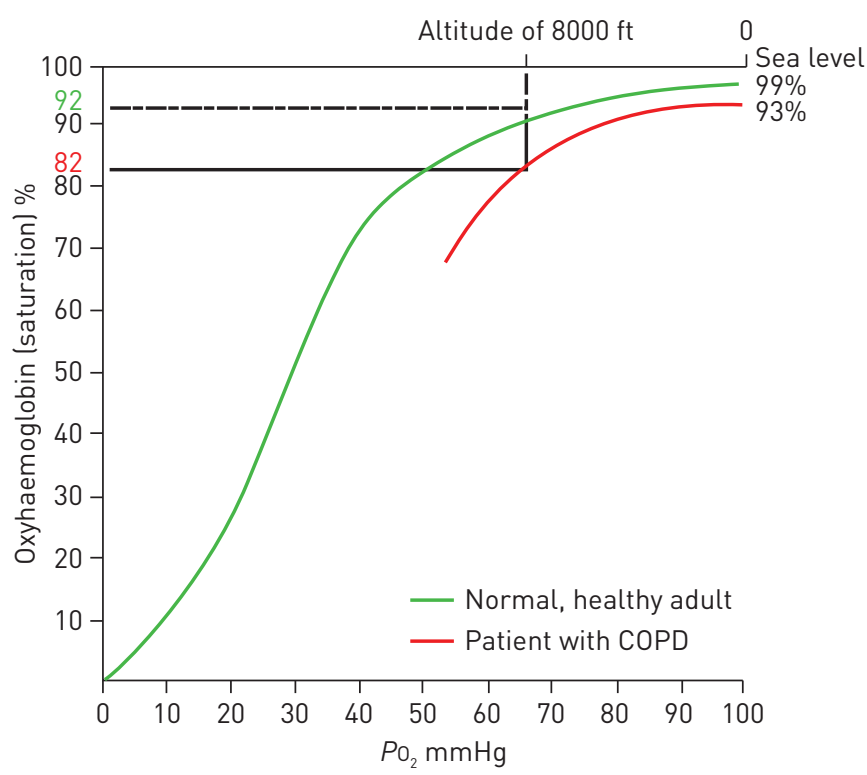


mismatch and helps to maintain $\mathrm{PaO}_{2}$ [25]. In a recent study consisting of 1260 healthy individuals, no significant changes occurred in arterial oxygen saturation measured by pulse oximetry $\left(\mathrm{SpO}_{2}\right)$ during a simulated $8 \mathrm{~h}$ flight [29]. However, if the flight altitude is $>3050 \mathrm{~m}(10000 \mathrm{ft})$, hypoxaemia becomes more prominent and $\mathrm{SaO}_{2}$ is $\sim 89 \%$ in a healthy individual [10]. Aircraft crew and all passengers must use supplemental oxygen when cabin pressure altitudes exceed this level in order to prevent hypoxaemia-related symptoms $[9,30]$. Supplemental oxygen has been shown to reverse altitude-induced hypoxaemia [31-33].

\section{The risk of flying with COPD}

Compared to healthy individuals, passengers with moderate-to-severe COPD have a higher risk for experiencing significant hypoxaemia during air travel $[30,31,33]$. People who already have reduced $\mathrm{PaO}_{2}$ have a further decline in $\mathrm{PaO}_{2}$, which may be below critical limits (figure 2). The physiological reserve of the patient determines the degree of hypoxaemia. Additionally, even minor exercise in these patients causes further decrease in $\mathrm{PaO}_{2}[30,34,35]$. Maximal aerobic exercise capacity is decreased at high altitudes due to a decrease in arterial oxygen content [23].

Theoretically, hypercapnia indicates poor pulmonary reserve in COPD and patients who have elevated arterial carbon dioxide tension $\left(\mathrm{PaCO}_{2}\right)$ may experience more severe hypoxaemia during flying. However, this issue is still controversial as there is limited data. Both simulation and in-flight studies showed that $\mathrm{PaCO}_{2}$ decreases in response to hypoxaemia-induced hyperventilation [33, 34]. Hypoxaemia-induced hyperventilation, in turn, may result in hyperinflation and, therefore, increased intrinsic positive end-expiratory pressure, which is mainly responsible for respiratory muscle fatigue in severe COPD especially during long-haul flights (figure 3) [28].

Pulmonary artery pressure increases due to hypoxic vasoconstriction during air travel even in healthy individuals without any pre-existing cardiopulmonary disease [36]. Increase in pulmonary artery pressure is more pronounced in COPD patients with pre-existing pulmonary hypertension. This may lead to an increase in right ventricle afterload and eventually right ventricular dysfunction [27, 37]. Acute hypoxaemia leads to sympathetic activation through peripheral chemoreceptors, which is responsible for increases in heart rate,

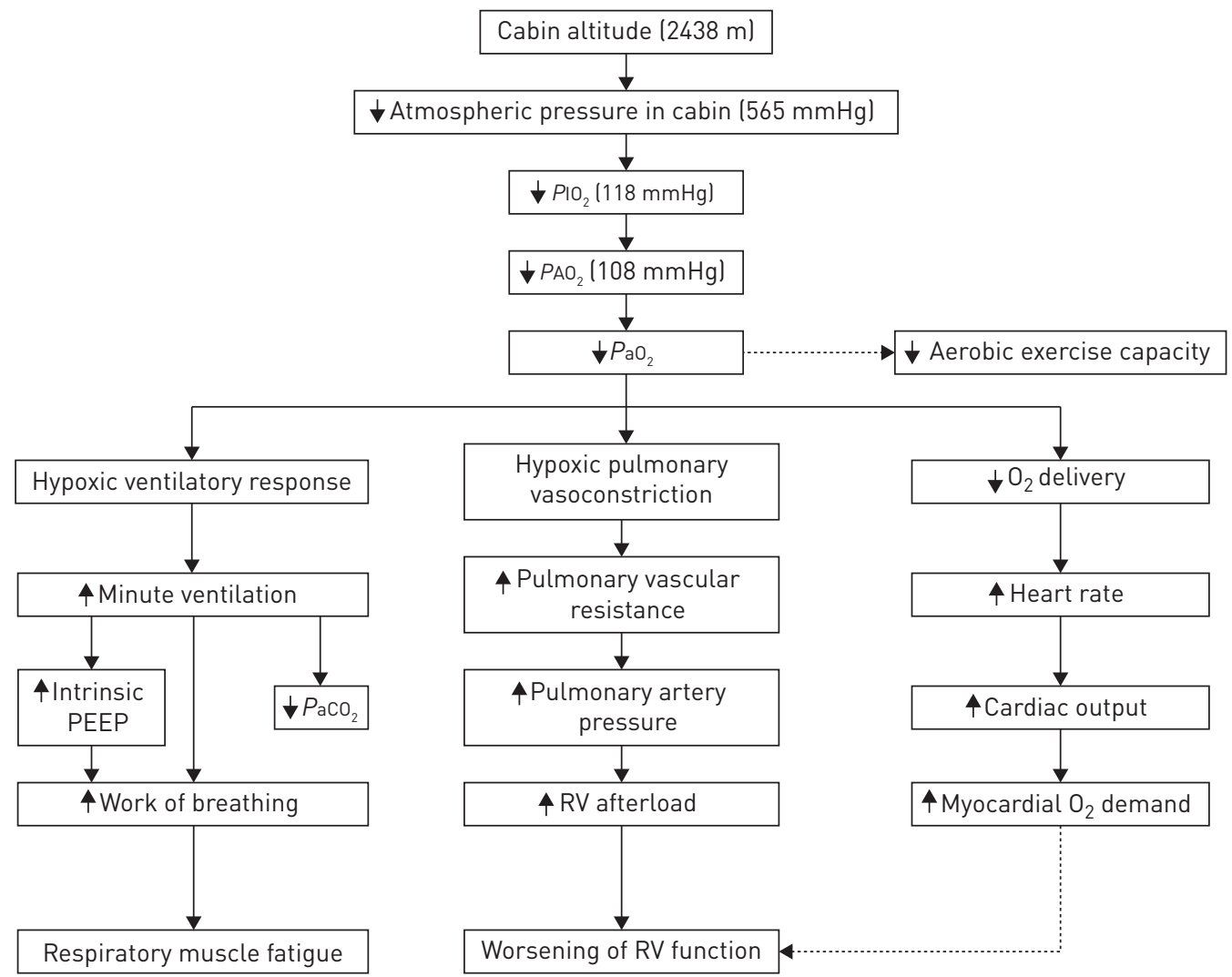

FIGURE 3 Pathophysiological changes in chronic obstructive pulmonary disease during air travel. $P_{\mathrm{IO}_{2}}$ : inspired oxygen tension; $P_{\mathrm{AO}_{2}}$ : alveolar oxygen tension; $P_{\mathrm{aO}}$ : arterial oxygen tension; $P_{\mathrm{aCO}}$ : arterial carbon dioxide tension; PEEP: positive end-expiratory pressure; RV: right ventricle. 
blood pressure, myocardial contraction velocity and cardiac output [38]. Life-threatening organ dysfunction such as cardiac arrhythmias and ischaemia and chest pain may occur in susceptible patients who are unable to respond sufficiently to these physiological requirements during flights $[33,39]$.

Falling asleep is a natural behaviour during long-haul flights. It has been shown that sleep may cause desaturations during flights, which are even more pronounced than those that occur during exercise [40]. Still, in healthy subjects, $\mathrm{SpO}_{2}$ stays within the acceptable range. However, sleep may cause relatively significant desaturations in COPD patients who are more vulnerable to hypoxaemia. During sleep, COPD patients without hypoxaemia at rest may experience severe nocturnal desaturations; patients who are already hypoxaemic may experience worsening of hypoxaemia [41]. In addition, taking alcohol or other sedatives, including sleeping pills, may exacerbate this problem by increasing sleepiness and actual sleep time.

During ascent, another problem is the expansion of gases. According to Boyle's law, the volume of gas is inversely proportionate to the pressure. Hence, at high altitudes, the volume of gas expands compared to its value at sea level. As an example, $1 \mathrm{~L}$ of gas will expand to $\sim 1.4 \mathrm{~L}$ at an altitude of $2450 \mathrm{~m} \mathrm{[42].} \mathrm{It} \mathrm{is}$ not a problem when all alveolar units are vented through the trachea; however, when the gas is confined in a closed unit such as blebs, rapid ascent may cause expansion of gases which may cause problems especially in COPD patients with bullous emphysema or previous history of pneumothorax [19, 43].

\section{Symptoms}

Although the majority of studies showed that COPD patients develop hypoxaemia during actual or simulated flights, few patients' experience severe symptom complications due to hypoxaemia. Individuals with limited cardiopulmonary reserve usually have symptoms, and in-flight emergencies due to hypoxaemia-related respiratory symptoms account for $9-12 \%[14,18,19]$. However this rate increases to $18 \%$ in patients with lung diseases [20]. In a study, 391 COPD patients were evaluated retrospectively and a quarter reported hypoxaemia-related symptoms [44]. Symptoms were strongly associated with severe breathlessness (higher dyspnoea scores) and exercise desaturation during a 6-min walk test. Compared to non-COPD controls, COPD patients had a seven-fold higher risk of experiencing dyspnoea and air hunger. Other than dyspnoea and air hunger, hyperventilation, light-headedness, chest pain, tingling in the extremities and palpitations may occur $[33,34]$. These insidious symptoms can be under-recognised both by the patients' themselves and clinicians. COPD patients may become more symptomatic with minimal activity like walking down the aisle or going to the toilet, especially on long-haul flights in which intermittent activity is encouraged.

In the current commercial fleet, the ratio of fresh air to re-circulated air is usually about 50:50 during the flight. [8]. Air density and temperature also decrease with ascent. The air inside the cabin is drawn from outside and then heated, filtered and humidified to 10-20\% and around 20 to 30 complete air exchanges occur per hour [45]. Low air humidity in the cabin may cause not only minor symptoms such as irritation and dehydration of the eyes, nose and upper airways but also respiratory symptoms due to irritation of the lower airways. These factors may increase insensible water loss and contribute to airway reactivity. Increased ventilation in response to hypoxaemia may also provoke dehydration of airway mucosa which in turn results in respiratory symptoms.

\section{Assessment for in-flight hypoxaemia in COPD}

There is still no consensus about which patient to refer before air travel and the gold standard test of assessment of hypoxaemia in COPD. COPD patients with dyspnoea on exertion, forced expiratory volume in $1 \mathrm{~s}\left(\mathrm{FEV}_{1}\right)<1.5 \mathrm{~L}$ or FEV1 $<30 \%$ predicted, a pre-existing requirement of oxygen/ventilatory support, bullous lung disease, comorbid conditions that may worsen hypoxaemia like cardiac disease and significant symptoms during previous air travel are considered as high risk and need further evaluation $[8,19,25,46]$.

General well-being, symptoms, recent exacerbation history and ongoing treatments should be evaluated and all COPD patients should undergo physical examination before a planned flight. The opinions of respiratory physicians regarding assessment methods and criteria for recommending in-flight oxygen seem to vary [7]. COKER et al. [20] evaluated patients who were referred for pre-flight assessment and the most common diagnoses for referral were COPD (39\%), diffuse parenchymal lung diseases excluding sarcoidosis (23\%), asthma (15\%), bronchiectasis (8\%) and sarcoidosis (7\%). The tests used for the pre-flight assessment were reported as oxygen saturation in $96 \%$, pulmonary function test in $95 \%$, hypoxic challenge test (HCT) in $45 \%$ and walk test in $10 \%$. Previous guidelines usually support the use of $\mathrm{SpO}_{2}$ as an initial step $[47,48]$. Depending on $\mathrm{SpO}_{2}$ value and other risk factors the patients may have, additional tests are helpful for risk stratification and need for supplemental oxygen on the aircraft. For COPD patients, we suggest using an algorithm that is developed using a combination of recent literature data (figure 4). 


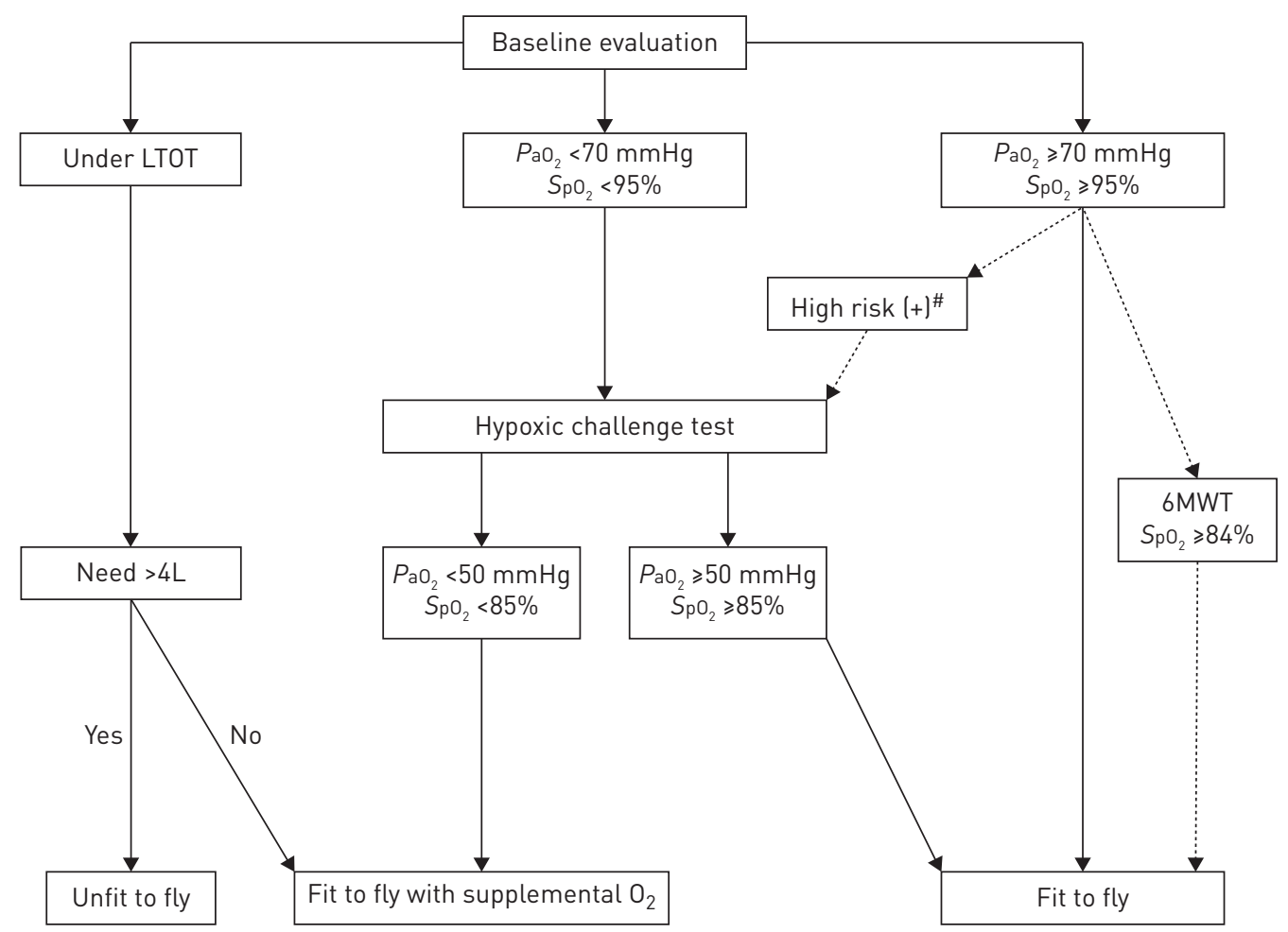

FIGURE 4 Algorithm for the assessment of fitness to fly in chronic obstructive pulmonary disease patients. LTOT: long-term oxygen therapy; $\mathrm{PaO}_{2}$ : arterial oxygen tension; $\mathrm{SpO}_{2}$ : arterial oxygen saturation measured by pulse oximetry; 6MWT: 6-min walk test. "\#: if dyspnoea on exertion, forced expiratory volume in $1 \mathrm{~s}<1.5 \mathrm{~L}$ or $<30 \%$ predicted, a pre-existing requirement of oxygen/ventilatory support, bullous lung disease, comorbid conditions that may worsen hypoxaemia like cardiac disease and significant symptoms during previous air travel.

Whatever the evaluation method, clinicians should make certain of two important points. First, patients should receive the optimal medical treatment according to disease severity and, secondly, patients must be in a stable period for a while, ideally at least 6 weeks, without any recent exacerbations.

\section{Tests used for pre-flight assessment Oxygen saturation}

The easiest way to evaluate a patient for fitness to fly is pulse oximetry. Measurement of pre-flight $\mathrm{SpO}_{2}$ is usually the first step used as a screening method [20]. It is usually accepted that for patients with a resting $\mathrm{SpO}_{2}>95 \%$ at sea level, the risk of hypoxaemia is relatively low and in-flight oxygen is not needed [47-49]. Patients with $\mathrm{SpO}_{2} \leqslant 95 \%$ need further testing, especially when there is a history of in-flight symptoms or an adverse event or cardiac comorbidity. However, these cut-off levels are mostly arbitrary and may not be sufficient enough to select patients with higher risk in COPD. AKERO et al. [50] divided 100 COPD patients into groups according to $\mathrm{SpO}_{2}$ and risk factors before performing HCT. It was seen that the percentage of patients who dropped to $\mathrm{PaO}_{2}<50 \mathrm{mmHg}(6.6 \mathrm{kPa})$ were: $30 \%$ in the $\mathrm{SpO}_{2}>95 \%$ group, $67 \%$ in the $\mathrm{SpO}_{2} 92-$ $95 \%$ and without additional risk factors group, $70 \%$ in the $\mathrm{SpO}_{2} 92-95 \%$ and additional risk factors group, and $83 \%$ in the $\mathrm{SpO}_{2}<92 \%$ group [50]. RoBSON et al. [49] also showed that one-third of patients with sea level $\mathrm{SpO}_{2}$ between $92 \%$ and $95 \%$ and with no any additional risk factor desaturated during HCT. With respect to these findings, pre-flight $\mathrm{SpO}_{2}$ alone seems to be an unreliable tool for the decision of fit to fly and does not help to discriminate COPD patients adequately for in-flight oxygen supplementation.

\section{Arterial blood gas analysis}

Pre-flight arterial blood gas analysis is usually needed if the patient's sea level $\mathrm{SpO}_{2}$ is $<95 \%$. The Aerospace Medical Association recommends sea level blood gas analysis as a baseline evaluation before flying in at-risk patients and a pre-flight $\mathrm{PaO}_{2}>70 \mathrm{mmHg}(9 \mathrm{kPa})$ is considered to be safe for flying without oxygen supplementation [46]. If the $\mathrm{PaO}_{2}$ level is not $>70 \mathrm{mmHg}$ then it is recommended to undergo pre-flight diagnostic evaluation either with a hypobaric chamber or HCT in a specialised centre.

However, the predictive value of $\mathrm{PaO}_{2}$ is questionable in COPD. Although earlier studies showed that sea level $\mathrm{PaO}_{2}$ correlated well with expected altitude $\mathrm{PaO}_{2}[33,51]$, consequent studies showed that sea level 
TABLE 1 Studies comprising patients with chronic obstructive pulmonary disease (COPD) for prediction of hypoxaemia during air travel

\begin{tabular}{|c|c|c|c|}
\hline Author [ref.] & Year & Patients & Test/condition used \\
\hline GoNG [33] & 1984 & 22 moderate COPD & HCT \\
\hline DiLLARD [51] & 1989 & 18 severe COPD & Hypobaric chamber \\
\hline SchWARTZ [52] & 1984 & 13 severe COPD & $\begin{array}{l}\text { Inflight } A B G \text { s at } 1650 \mathrm{~m} \text { and } \\
2250 \mathrm{~m}\end{array}$ \\
\hline
\end{tabular}

$\begin{array}{llll}\text { Berg [31] } & 1992 & 18 \text { severe COPD } & \text { Hypobaric chamber } \\ \text { ChRISTEnSEN [30] } & 2000 & 15 \text { severe COPD } & \text { HCT }\end{array}$

$\begin{array}{llcl}\text { Robson [53] } & 2000 & \begin{array}{c}20 \text { COPD (15 severe) } \\ \text { and } 8 \text { other RD }\end{array} & \text { HCT } \\ \text { Seccombe [35] } & 2004 & 10 \text { COPD and 15 ILD } & \text { HCT with 50-m walk test }\end{array}$

AKERo [34] $2005 \quad 18$ COPD In-flight ABG

$\begin{array}{lll}\text { Chetta [54] } & 2007 & 15 \text { COPD and 15 ILD } \\ \text { KeLLy [55] } & 2008 & 13 \text { severe COPD }\end{array}$

AKERO [50]

2008100 COPD

RoBson [49]

200874 COPD and 44 other RD

HCT

KeLLY [56]

200918 severe COPD

Mount Hutt (2086 m altitude)

$\mathrm{HCT}$ and $6 \mathrm{MWT}$
In-flight $\mathrm{SpO}_{2}$, post-flight $\mathrm{HCT}$ and $6 \mathrm{MWT}$

HCT

Edvardsen [57] 2012100 severe COPD HCT and 6MWT

EdVARDSEn [58]

201382 moderate-to-severe COPD

\section{Results}

Sea level $\mathrm{PaO}_{2}$ predicted acute resting altitude $\mathrm{PaO}_{2}$

Ground $\mathrm{PaO}_{2}$ correlated with expected altitude $\mathrm{PaO}_{2}$, combination of $\mathrm{FEV} 1$ and ground $\mathrm{PaO}_{2}$ improved prediction of $\mathrm{PaO}_{2}$ at $8000 \mathrm{ft}$

$\mathrm{PaO}_{2}$ measured $<2 \mathrm{~h}$ before the flight in room air or a $17.2 \%$ oxygen mixture correlated with $\mathrm{PaO}_{2}$ at $1650 \mathrm{~m} . \mathrm{PaO}_{2}$ measured several weeks before flight did not correlate with any in-flight measurements

Oxygen supplementation via nasal cannula or Venturi mask corrects altitude hypoxaemia

Pre-flight $\mathrm{PaO}_{2}>70 \mathrm{mmHg}$, FEV1 or TLCo values do not predict altitude hypoxaemia. Light exercise may provoke hypoxaemia and there was a correlation between aerobic capacity and altitude $\mathrm{PaO}_{2}$

Altitude $\mathrm{PaO}_{2}$ could not be predicted from either $\mathrm{FEV} 1$ or pre-test $\mathrm{SpO}_{2}$

Resting sea level $\mathrm{PaO}_{2}$ is poor for predicting the hypoxaemic response in both COPD and ILD groups. Means of $P_{\mathrm{aO}}$ of both groups fell below recommended levels at both resting and when walking during HCT

Significant desaturations were observed during flight, which were worsened with activity. A pre-flight $P_{\mathrm{aO}}>70 \mathrm{mmHg}$ did not predict in-flight hypoxaemia. Aerobic capacity showed the strongest correlation with in-flight $\mathrm{PaO}_{2}$

$\mathrm{SpO}_{2}$ in 6MWT can predict oxygen desaturation during HCT

Significant desaturations were observed during flight, which were worsened with activity. $\mathrm{HCT} \mathrm{S \textrm {SO } _ { 2 }}$ was well correlated with in-flight $\mathrm{SpO}_{2}$. Resting $\mathrm{PaO}_{2}$ and the post-flight 6MWT result did not correlate with in-flight $\mathrm{SpO}_{2}$

Pre-flight $\mathrm{SpO}_{2}$ does not help to discriminate patients adequately for in-flight $\mathrm{O}_{2}$ supplementation. $30 \%$ of patients with pre-flight $\mathrm{SpO}_{2}>95 \%$ and $67 \%$ of patients with pre-flight $\mathrm{SpO}_{2}$ between $92-95 \%$ and without additional risk factors dropped $\mathrm{PaO}_{2}$ below $50 \mathrm{mmHg}$ during HCT

Desaturation during HCT cannot be predicted reliably from either $\mathrm{FEV} 1$ or sea level $\mathrm{SpO}_{2}$. All patients with sea level $\mathrm{SpO}_{2}>95 \%$ maintained $\mathrm{O}_{2}$ saturation $>90 \%$ during $\mathrm{HCT}$. One-third of patients with sea level $\mathrm{SpO}_{2}$ between $92-95 \%$ and with no risk factor desaturated during HCT

Ascent from sea level to altitude caused significant hypoxaemia $\left(\mathrm{PaO}_{2} 75 \pm 9\right.$ versus $51 \pm 6 \mathrm{mmHg}$, respectively), and worsened during walk test $(41 \pm 7 \mathrm{mmHg})$ which was partially reversed by supplemental oxygen $(64 \pm 9 \mathrm{mmHg}$ ). $\mathrm{KcO}$ correlated both with resting altitude $\mathrm{SaO}_{2}$ and exercise $\mathrm{PaO}_{2}$

An algorithm was constructed using a combination of resting and $6 \mathrm{MWT} \mathrm{SpO}_{2}$. Resting $\mathrm{SpO}_{2}>95 \%$ combined with $6 \mathrm{MWT} \mathrm{SpO}_{2}>84 \%$ had a sensitivity of $100 \%$ and specificity of $80 \%$ for fitness to fly

Post-flight questionnaire results showed that there was no difference in $\mathrm{HCT} \mathrm{PaO}_{2}$ between patients with and without symptoms; however, planned use of in-flight supplemental oxygen in patients with $\mathrm{HCT} \mathrm{PaO}_{2}$ $<50 \mathrm{mmHg}$ resulted in a lower frequency of respiratory symptoms

RD: respiratory disease; ILD: interstitial lung disease; HCT: hypoxic challenge test; ABG: arterial blood gas; 6MWT: 6-min walk test; SpO ${ }_{2}$ : arterial oxygen saturation measured by pulse oximetry; $\mathrm{PaO}_{2}$ : arterial oxygen tension; $\mathrm{FEV} 1$ : forced expiratory volume in $1 \mathrm{~s}$; $T \mathrm{LCO}$ : transfer factor of the lung for carbon monoxide; Kco: transfer coefficient of the lung for carbon monoxide. 
$\mathrm{PaO}_{2}$ may not be predictive for desaturation during flying in COPD (table 1) [30, 34, 35, 52]. Christensen et al. [30] studied severe COPD patients and showed that a sea level $\mathrm{PaO}_{2}>70 \mathrm{mmHg}$ does not exclude the development of severe hypoxaemia. An interesting finding was even minor exercise, such as walking along the aisle, induced severe hypoxaemia in these patients. Desaturation with exercise, assessed with the 50-m walk test, in COPD patients was also shown in another study in which the post-exercise $\mathrm{PaO}_{2}$ is $6 \mathrm{mmHg}$ which is lower than pre-exercise values [35]. Akero et al. [34] performed an in-flight study and evaluated arterial blood gas on board in 18 moderate-to-severe COPD patients. Pre-test $\mathrm{SpO}_{2}$ was $>94 \%$ in all patients and they had all passed the 50-m walk test. It was shown that there was a decrease in mean $\mathrm{PaO}_{2}$ from 77 to $64.5 \mathrm{mmHg}$ and it remained stable throughout the flight (about $6 \mathrm{~h}$ ) in all patients except one. In this cohort, pre-flight $P_{a} O_{2}>70 \mathrm{mmHg}$ did not predict an acceptable in-flight $\mathrm{PaO}_{2}$. Although five patients desaturated more than the acceptable range, none of them had any clinical worsening.

\section{Pulmonary function tests}

In the absence of any contraindication, spirometry is advised in patients with a history of acute or chronic lung disease or with symptoms suggestive of lung disease [25, 28]. However, lung function parameters failed to predict either hypoxaemia or complications [30, 49, 53, 59]. The results about diffusing capacity are conflicting as well, but it was previously shown in one study that patients with diffusion impairments are likely to experience the greatest altitude desaturations [56]. However, DilLard et al. [60] reported that using FEV1 as an additional parameter might improve predictive yield for estimating in-flight $P_{\mathrm{aO}}$. Some authors also suggest using maximal voluntary ventilation (MVV) [25, 60]. Patients with a MVV $<40 \mathrm{~L} \cdot \mathrm{min}^{-1}$ are considered as high risk for decompensation during air travel.

\section{Walk tests}

Practically, patients who can complete a 50-m walk (or climb 10-12 stairs) without any distress are considered to have sufficient cardiopulmonary reserve for flying $[8,47]$. Recently, the 6-min walk test has become more popular and is often used for the assessment of functional capacity and exercise-induced hypoxaemia in COPD patients $[41,54,55,57,61]$. ChetTA et al. [54] showed that $\mathrm{SpO}_{2}$ during 6-min walk test could predict in-flight oxygen desaturations. In a recent study, an algorithm using both resting and 6-min walk test $\mathrm{SpO}_{2}$ values may be a reliable tool for estimation desaturation during flying [57]. Resting $\mathrm{SpO}_{2}>95 \%$ combined with a 6 -min walk test $\mathrm{SpO}_{2}>84 \%$ had a sensitivity of $100 \%$ and specificity of $80 \%$ for "fitness to fly". The results of this study deserve specific attention and must be validated with new studies as: 1) it shows good correlation with HCT; and 2) it is an easy and inexpensive test that is currently being performed in many centres.

\section{Predictive equations for estimation of hypoxaemia}

Several equations were offered for the estimation of in-flight $\mathrm{PaO}_{2}$ both in healthy individuals and patients with COPD $[19,62,63]$. Some of these equations just use sea level $\mathrm{PaO}_{2}$ whereas others also take into account $P_{\mathrm{aCO}_{2}}, \mathrm{FEV} 1, \mathrm{FEV} 1 /$ forced vital capacity and diffusing capacity which may improve the accuracy of predicted value. In a meta-analysis, multiple regression equations have been found to be a good estimate for $\mathrm{PaO}_{2}$ at $8000 \mathrm{ft}$ in normocapnic COPD patients [62]. One drawback is there are huge variations among equations and poor agreement with altitude simulated $\mathrm{PaO}_{2}$ [64-66]. BRADI et al. [65] compared 16 predictive equation formulas with HCT in 27 subjects (22 with COPD) and showed that predictive equations provide poor estimates of $\mathrm{PaO}_{2}$ measured during HCT. In addition, predictive equations reported overestimating in-flight $\mathrm{O}_{2}$ need when compared to altitude simulation [64]. More validation studies are required for these equations for routine use especially in the COPD population.

\section{Hypoxic challenge test}

HCT (also known as hypoxia altitude simulation test, high altitude simulation test or normobaric hypoxia inhalation test) is the simulation of an aircraft cabin with decreased inspiratory oxygen fraction $\left(F \mathrm{IO}_{2}\right)$ in the normobaric environment. The test is considered a reliable tool in predicting hypoxaemia measured during air travel both in healthy subjects and COPD patients [37]. It was shown that $\mathrm{SpO}_{2}$ in HCT was well correlated with in-flight mean $\mathrm{SpO}_{2}$ [22]. However, in a recent study $\mathrm{PaO}_{2}$ in HCT was not associated with the presence of symptoms during air travel [58]. Referral to HCT is usually due to a $\mathrm{SaO}_{2}$ value $<92-95 \%$ at sea level or suspicion of possible in-flight hypoxaemia. Patients who experienced symptoms that may be considered as a consequence of desaturations are also candidates for HCT.

At an altitude of $2438 \mathrm{~m}, \mathrm{FIO}_{2}$ inside the aircraft is $15.1 \%$. Therefore, the test begins with the subject breathing a mixture of gas containing $15 \% \mathrm{O}_{2}$ from a tight fitting mask for $20 \mathrm{~min}$. The patient is monitored for symptoms, $\mathrm{S}_{\mathrm{PO}_{2}}$ and change in vital signs including heart rate during the whole period. After $20 \mathrm{~min}$, an arterial blood gas is performed for evaluation. If the $\mathrm{PaO}_{2}$ level is $>50 \mathrm{mmHg}\left(\mathrm{SpO}_{2}\right.$ 
$\geqslant 85 \%)$, supplemental oxygen is not required for the flight [19]. If $\mathrm{PaO}_{2}$ is $<50 \mathrm{mmHg}\left(\mathrm{SpO}_{2}<85 \%\right)$, the test can be repeated with supplemental oxygen at a usual rate of $2-4 \mathrm{~L} \cdot \mathrm{min}^{-1}$ [37].

Although HCT is used for the prediction of in-flight hypoxaemia, the clinical relevance of the test has not been validated and further research is needed to determine its actual place in the pre-flight assessment of respiratory patients $[7,19,67]$. In addition, even $\mathrm{PaO}_{2}$ during HCT is well correlated with the in-flight $\mathrm{PaO}_{2}$ level; it has limited predictive value for prediction of in-flight symptom occurrence. Another important drawback of the technique is HCT should be conducted at specialised centres with advanced equipment and monitoring options and medical staff experienced in performing the test.

\section{Hypobaric chamber test}

The hypobaric chamber test simulates the hypobaric environment of an aircraft cabin altitude of $2438 \mathrm{~m}$. However, this test is generally only used for research purposes.

\section{How should COPD patients be prepared for flying?}

All passengers with COPD need to be evaluated for risk for flying and every intervention to decrease the risk and prevent an adverse event should be encouraged. Past medical history including comorbidities and ongoing treatments, clinical assessment, discussion about flying, any previous flying history of symptoms and possible risks and contraindications should be assessed. Co-existence of pulmonary and cardiac diseases needs specific consideration because of the close interactions between the two systems.

Preparation before flying consists of optimisation of COPD treatment, the risk for in-flight hypoxaemia and supplementation of oxygen when needed. Most of the time, these steps are performed in oxygen-dependent patients with chronic respiratory failure and skipped in less severe COPD patients but, ideally, all COPD patients need to know that they should seek medical advice before flying. For patients with a bullous disease or previous history of pneumothorax, a pre-flight chest radiograph is encouraged [19].

Family physicians are usually the first healthcare provider before air travel and therefore should also get involved and educate patients on the risks of flying, as well as increasing awareness and educating COPD patients. Travel should be postponed, optimally for 6 weeks, in case of a recent exacerbation. All therapies that the patient is taking should be reviewed and prescribed as so cover the duration of travel. In addition, health insurance coverage both for additional treatments and hospitalisations that may be needed should also be pre-planned. Patients may have a frequent travellers medical card (FREMEC); this avoids the necessity to obtain medical clearance for each journey and describes the passenger's medical needs and special handling requirements. [8]. Several websites are now available for information both for patients and healthcare providers (table 2).

During the flight, patients should keep all medications within reach on board, take direct flights, ensure adequate hydration, do intermittent leg exercises and select a seat near to the toilets, preferably on an aisle. Patients who are at-risk for desaturation during sleep should be warned about avoiding alcohol intake and other sedatives during long flights.

TABLE 2 Useful information websites for air travel

\begin{tabular}{|c|c|c|}
\hline Organisation & Website & Contents \\
\hline Aerospace Medical Association & www.asma.org & Health tips for passengers and health professionals \\
\hline British Lung Foundation & www.blf.org.uk & Information and support website \\
\hline Centers for Disease Control & wwwnc.cdc.gov/travel & Travellers' health website for individuals and healthcare providers \\
\hline Civil Aviation Authority & www.caa.co.uk/Passengers & Medical information for passengers and healthcare providers \\
\hline European Lung Foundation & www.europeanlung.org & Information and medical tips for air travel \\
\hline International Air Transport Association & www.iata.org & Medical manual for air travel \\
\hline International Civil Aviation Organization & www.icao.int & $\begin{array}{l}\text { Manual of civil aviation medicine for flying personnel and healthcare } \\
\text { providers }\end{array}$ \\
\hline International Society of Travel Medicine & www.istm.org & Online learning programmes for healthcare providers \\
\hline
\end{tabular}




\section{Oxygen supplementation}

The safe threshold for oxygenation is to keep $\mathrm{PaO}_{2}>50 \mathrm{mmHg}$ and $\mathrm{SpO}_{2} \geqslant 85 \%$ during the flight. Oxygen supplementation should be considered in patients who are expected to have lower values during air travel. It was shown that patients with supplementation reported having fewer symptoms during a flight [58].

Supplemental oxygen systems can be arranged either by the patient themselves or by the airline. Current regulations, with possible costs, of many airlines can be found in the European Federation of Allergy and Airways Diseases Patients' Association booklet on enabling air travel with oxygen in Europe [68]. Patients receiving long-term oxygen therapy can take their own cylinders if the airline accepts. Therefore, checking with the airline about these options should be encouraged. Passengers are responsible for notifying the airline about their needs and acting accordingly.

Oxygen supplementation can be obtained by the airline after a report indicating oxygen requirement and its prescription by the physician. Usually, flight approved compressed gas cylinders are the first choice option for short flights $[28,69]$, but portable oxygen concentrators are more convenient, especially for long-haul flights. It can also be used on the ground during transit. Many airlines also accept pulsed systems. However, in a study comparing different sources of supplemental oxygen, compressed gas with continuous flow and an oxygen-conserving device resulted in the same $\mathrm{PaO}_{2}$ whereas a portable oxygen concentrator showed significantly lower $\mathrm{PaO}_{2}$ values. In order to achieve the acceptable $\mathrm{PaO}_{2}$ values, it is advised to increase the flow in portable concentrators [70]. The battery life and maximum possible oxygen output should also be taken care of, as it may be a problem for long flights [71]. The main responsibility for flying belongs to the patient but according to regulatory laws, airlines can also refuse carriage of the patient if there is a safety concern $[8,19]$.

Supplemental oxygen delivered at $2-4 \mathrm{~L} \cdot \mathrm{min}^{-1}$ should maintain clinically acceptable oxygenation during commercial air travel in most patients with COPD. For patients who are already on long-term oxygen therapy it is usually advised to double the flow rate, however, patients who need oxygen $>4 \mathrm{~L} \cdot \mathrm{min}^{-1}$ at sea level may be unable to travel as most airlines cannot deliver oxygen with a double rate. Patients with long-term oxygen therapy should also plan their oxygen supplementation to their final destination.

A nasal cannula is the most commonly used option for delivery and the International Air Transport Association reports using a nasal cannula system as the delivery of oxygen is similar to a mask [72]. Depending on patients' clinical status, the Venturi mask can be an option for assuring a certain $\mathrm{FIO}_{2}$ in patients who are susceptible for depression in respiratory drive with high flows of oxygen [31].

Supplemental oxygen may cause beneficial haemodynamic changes and correct arrhythmia caused by hypoxaemia in patients with COPD during acute hypobaric exposure [39]; however, nifedipine may be an option to prevent worsening of right heart function in patients with severe pulmonary hypertension due to COPD [27].

Of note, use of first-aid oxygen bottles and drop-down oxygen masks for supplementation is prohibited as most airlines carry a very limited supply of oxygen which is only to be used in case of an emergency, such as depressurisation of the cabin [46].

\section{Other problems}

Jet lag, loss of circadian rhythm and sleep disturbances may be an important problem, especially in overseas flights. General advice and treatment options for jet lag (sleep hygiene, melatonin, etc.) are also valid for COPD patients.

It has been shown that hypoxaemia can cause coagulation activation in COPD patients [73]. The risk increases after $4 \mathrm{~h}$ and peaks at $8 \mathrm{~h}$ [74]. Patients with low risk should be warned to avoid tight clothing below the waist and try to rehydrate during the flight. Moving along the aisle may be an option for patients without risk of desaturation. If the patient has a risk of desaturation, below knee compression stockings and calf stretching exercises while sitting may be a safe alternative [75]. Patients with high risk of thromboembolism (previous venous thromboembolism history, known active malignancy, known thrombophilia, and major surgery within 6 weeks) should ask for individual help for prophylactic low molecular weight heparin.

Aircraft cabin air quality during flights is generally acceptable and often better than many other indoor environments [8]. Although the air inside the cabin is circulated by $50 \%$ of total and high-efficiency particulate air filters are used, there is still a risk of infection transmission. The outbreak of severe acute respiratory syndrome drew attention to the transmission of infection during air travel. Respiratory viruses and influenza may be a considerable problem in COPD patients as they are responsible for a high percentage of exacerbations. Patients should be warned, especially for outbreaks, and should be advised to postpone travel if necessary. 


\section{Conclusion}

With optimised care, patients can fly without any additional risk. Clinical and functional evaluation for fitness to fly and possible risk factors for in-flight hypoxaemia should be assessed in all COPD patients before flying. From the literature reports so far, it seems reasonable to conclude that many patients tolerate significant hypoxaemia without any symptoms or an adverse event. However, proactive strategies to identify patients at risk and implementing preventive measures for adverse events in high-risk patients should be encouraged in order to achieve better disease management. We have to keep in mind that it is now time to take care of our patients, not only on the ground but also in the air.

Conflict of interest: None declared.

\section{References}

1 World Health Organization. Burden of COPD. www.who.int/respiratory/copd/burden/en/ Date last accessed: January 20, 2018.

2 GBD 2015 Mortality and causes of death collaborators. Global, regional, and national life expectancy, all-cause mortality, and cause specific mortality for 249 causes of death, 1980-2015: a systematic analysis for the Global Burden of Disease Study 2015. Lancet 2016; 388: 1459-1544.

3 Global Strategy for the Diagnosis, Management and Prevention of COPD. Global Initiative for Chronic Obstructive Lung Disease (2017). http://goldcopd.org Date last accessed: March 7, 2018.

4 The World Bank. Air transport, passengers carried. https://data.worldbank.org/indicator/IS.AIR.PSGR Date last accessed: March 7, 2017.

5 Gong H, Mark JL, Cowan MN. Preflight medical screenings of patients. Analysis of health and flight characteristics. Chest 1993; 104: 788-794.

6 Silverman D, Gendreau M. Medical issues associated with commercial flights. Lancet 2008; 373: 2067-2077.

$7 \quad$ Naeije R. Preflight medical screening of patients. Eur Respir J 2000; 16: 197-199.

8 IATA. Medical Manual, 10th edition. February 2018. www.iata.org/publications/Documents/medical-manual.pdf Date last accessed: March 7, 2018.

9 Aerospace Medical Association, Aviation Safety Committee, Civil Aviation Subcommittee. Cabin cruising altitudes for regular transport aircraft. Aviat Space Environ Med 2008; 79: 433-439.

10 International Civil Aviation Organization. Manual of Civil Aviation Medicine. 3rd edition, 2012. www.icao.int/ publications/Documents/8984_cons_en.pdf Date last accessed: February 28, 2018.

11 Hampson NB, Kregenow DA, Mahoney AM, et al. Altitude exposures during commercial flight: a reapraisal. Aviat Space Environ Med 2013; 84: 27-31.

12 Kelly PT, Seccombe LM, Rogers PG, et al. Directly measured cabin pressure conditions during Boeing747-400 commercial aircraft flights. Respirology 2007; 12: 511-515.

13 Seccombe LM, Peters MJ. Oxygen supplementation for chronic obstructive pulmonary disease patients during travel. Curr Opin Pulm Med 2006; 12: 140-144.

14 Peterson D, Martin-Gill C, Guyette FX, et al. Outcomes of medical emergencies on commercial airline flights. N Eng J Med 2013; 368: 2075-2083.

15 Graf J, Stüben U, Pump S. In-flight medical emergencies. Dtsch Arztebl Int 2012; 109: 591-601.

16 Qureshi A, Porter KM. Emergencies in the air. Emerg Med J 2005; 22: 658-659.

17 Hinkelbein J, Spelten O, Wetsch WA, et al. Emergencies in the sky: in-flight medical emergencies during commercial air transport. Trends Anesth Crit Care 2013; 3: 179-182.

18 Hinkelbein J, Neuhaus C, Böhm L, et al. In-flight medical emergencies during airline operations: a survey of physicians on the incidence, nature, and available medical equipment. Open Acc Emergency Med 2017; 9: 31-35.

19 Ahmedzai S, Balfour-Lynn IM, Bewick T, et al. Managing passengers with stable respiratory disease planning air travel: British Thoracic Society recommendations. Thorax 2011; 66: i1-i130.

20 Coker RK, Shiner RJ, Partridge MR. Is air travel safe for those with lung disease? Eur Respir J 2007; 30: $1057-1063$.

21 Harding RM, Mills FJ. Aviation medicine. problems of altitude 1: hypoxemia and hyperventilation. $\mathrm{Br} \mathrm{Med} J \mathrm{1983}$; 286: $1408-1410$.

22 Kelly PT, Swanney MP, Frampton C, et al. Normobaric hypoxia inhalation test $v s$ response to airline flight in healthy passengers. Aviat Space Environ Med 2006; 77: 1143-1147.

23 Wiseman RL, Kelly PT, Swanney MP, et al. Hypoxemia in health subjects in moderate altitude. Aviat Space Environ Med 2013; 84: 22-26.

24 Cottrell JJ, Lebowitz BL, Fennell RG, et al. Inflight arterial saturation: continuous monitoring by pulse oximetry. Aviat Space Environ Med 1995; 66: 126-130.

25 Mohr LC. Hypoxia during air travel in adults with pulmonary disease. Am J Med Sci 2008; 335: 71-79.

26 Carvalho AM, Poirier V. So you think you can fly? Determining if your emergency department patient is fit for air travel. Can Fam Phys 2009; 55: 992-995.

27 Stream JO, Luks AM, Grissom CK. Lung disease at high altitude. Expert Rev Respir Med 2009; 3: 635-650.

28 Nicholson TT, Sznader JI. Fitness to fly in patients with lung disease. Ann Am Thorac Soc 2014; 11: 1614-1622.

29 Health effects of airline cabin environments in simulated 8-hour flights. Aerosp Med Hum Perform 2017; 88: 651-656.

30 Christensen CC, Ryg M, Refvem OK, et al. Development of severe hypoxaemia in chronic obstructive pulmonary disease patients at 2,438 m (8,000 ft) altitude. Eur Respir J 2000; 15: 635-639.

31 Berg BW, Dillard TA, Rajagopal KR, et al. Oxygen supplementation during air travel in patients with chronic obstructive pulmonary disease. Chest 1992; 101: 638-641.

32 Cramer D, Ward S, Geddes D. Assessment of oxygen supplementation during air travel. Thorax 1996; 51: 202-203.

33 Gong H Jr, Tashkin DP, Lee EY, et al. Hypoxia-altitude simulation test. Evaluation of patients with chronic airway obstruction. Am Rev Respir Dis 1984; 130: 980-986. 
34 Akero A, Christensen CC, Edvardsen A, et al. Hypoxaemia in chronic obstructive pulmonary disease patients during a commercial flight. Eur Respir J 2005; 25: 725-730.

35 Seccombe LM, Kelly PT, Wong CK, et al. Effect of simulated commercial flight on oxygenation in patients with interstitial lung disease and chronic obstructive pulmonary disease. Thorax 2004; 59: 966-970.

36 Smith TG, Talbot NP, Chang RW, et al. Pulmonary artery pressure increases during commercial air travel in healthy passengers. Aviat Space Environ Med 2012; 83: 673-676.

37 Tzani P, Pisi G, Aiello M, et al. Flying with respiratory disease. Respiration 2010; 80: 161-170.

38 Bartsch P, Gibbs SR. Effect of altitiude on the heart and the lungs. Circulation 2007; 116: 2191-2202.

39 Berg BW, Dillard TA, Derderian SS, et al. Hemodynamic effects of altitude exposure and oxygen administration in chronic obstructive pulmonary disease. Am J Med 1993; 94: 407-412.

40 Muhm JM, Rock PB, McMullin DL, et al. Effect of aircraft-cabin altitude on passenger discomfort. $N$ Eng J Med 2007; 357: 18-27.

41 Ergan B, Nava S. Long-term oxygen therapy in COPD patients who do not meet the actual recommendations. COPD 2017; 14: 351-366.

42 Johnson AO. Chronic obstructive pulmonary disease 11: fitness to fly. Thorax 2003; 58: 729-732.

43 Harding RM, Mills FJ. Problems of altitude II: decompression sickness and other effects of pressure changes. Br Med J (Clin Res Ed) 1983; 286: 1498-1500.

44 Edvardsen A, Akero A, Hardle JA, et al. High prevalence of respiratory symptoms during air travel in patients with COPD. Respir Med 2011; 105: 50-56.

45 Rayman RB. Cabin air quality. Aviat Space Environ Med 2002; 73: 211-215.

46 Aerospace Medical Association. Medical guidelines for air travel. 2nd edition. Aviat Space Environ Med 2003; 74: Suppl, A1-A19.

47 British Thoracic Society Standards of Care Committee. Managing passengers with respiratory disease planning air travel: British Thoracic Society recommendations. Thorax 2002; 57: 289-304.

48 Josephs LK, Coker RK, Thomas M, et al. Managing patients with stable respiratory disease planning air travel: a primary care summary of the British Thoracic Society recommendations. Prim Care Respir J 2013; 22: 234-238.

49 Robson AG, Lenney J, Innes JA. Using laboratory measurements to predict in-flight desaturation in respiratory patients: are current guidelines appropriate? Respir Med 2008; 102: 1592-1597.

50 Akero A, Christensen CC, Edvardsen A, et al. Pulse oximetry in the preflight evaluation of patients with chronic obstructive pulmonary disease. Aviat Space Environ Med 2008; 79: 518-524.

51 Dillard TA, Berg BW, Rajagopal KR, et al. Hypoxemia during air travel in patients with chronic obstructive pulmonary disease. Ann Intern Med 1989; 111: 362-367.

52 Schwartz JS, Bencowitz HZ, Moser KM. Air travel hypoxemia with chronic obstructive pulmonary disease. Ann Intern Med 1984; 100: 473-477.

53 Robson AG, Hartung TK, Innes JA. Laboratory assessment of fitness to fly in patients with lung disease: a practical approach. Eur Respir J 2000; 16: 214-219.

54 Chetta $\mathrm{A}$, Castagnetti $\mathrm{C}$, Aiello $\mathrm{M}$, et al. Walking capacity and fitness to fly in patients with chronic respiratory disease. Aviat Space Environ Med 2007; 78: 789-792.

55 Kelly PT, Swanney MP, Seccombe LM, et al. Air travel hypoxemia $v$ s the hypoxia inhalation test in passengers with COPD. Chest 2008; 133: 920-926.

56 Kelly PT, Swanney MP, Stanton JD, et al. Resting and exercise response to altitude in patients with chronic obstructive pulmonary disease. Aviat Space Environ Med 2009; 80: 102-107.

57 Edvardsen A, Akero A, Christensen CC, et al. Air travel and chronic obstructive pulmonry disease: a new algorithm for preflight evaluation. Thorax 2012; 67: 964-969.

58 Edvardsen A, Ryg M, Akero A, et al. COPD and air travel: does hypoxia-altitude simulation testing predict in-flight respiratory symptoms? Eur Respir J 2013; 42: 1216-1223.

59 Ling IT, Singh B, James AL, et al. Vital capacity and oxygen saturation at rest and after exercise predict hypoxemia during hypoxic inhalation test in patients with respiratory disease. Respirology 2013; 18: 507-513.

60 Dillard TA, Rajagopal KR, Slivka WA, et al. Lung function during moderate hypobaric hypoxia in normal subjects and patients with chronic obstructive pulmonary disease. Aviat Space Environ Med 1998; 69: 979-985.

61 Brown CD, Wise RA. Field tests of exercise in COPD. The six-minute walk test and the shuttle walk test. COPD 2007; 4: 217-223.

62 Dillard TA, Rosenberg AP, Berg BW. Hypoxemia during high altitude: a meta-analysis of chronic obstructive pulmonary disease. Chest 1993; 103: 422-425.

63 Dillard TA, Moores LK, Bilello KL, et al. The preflight evaluation: a comparison of the hypoxia inhalation test with hypobaric exposure. Chest 1995; 107: 352-357.

64 Martin SE, Bradley JM, Bucik JB, et al. Flight assessment in patients with respiratory diseases: hypoxic challenge testing vs predictive equations. QJM 2007; 100: 361-367.

65 Bradi AC, Faughnan ME, Stanbrook MB, et al. Predicting the need for supplemental oxygen during airline flight in patients with chronic obstructive pulmonary disease: a comparison of predictive equations and altitude simulation. Can Respir J 2009; 16: 119-124.

66 Billings CG, Wei HL, Thomas P, et al. The prediction of in-flight hypoxaemia using non-linear equations. Respir Med 2013; 107: 841-847.

67 Howard LS. Last call for flight simulation test? Eur Respir J 2013; 2013: 1175-1177.

68 European Federation of Allergy and Airways Diseases Patients' Associations (EFA). Enabling air travel with oxygen in Europe. An EFA booklet for patients with chronic respiratory disease. www.efanet.org/images/2013/09/ Enabling-Air-Travel-with-Oxygen-in-Europe-An-EFA-Booklet-for-Patients-with-Chronic-Respiratory-Disease.pdf Date last accessed: March 7, 2018.

69 United States Department of Transportation. Federal Aviation Administration. FAA approved portable oxygen concentrators - positive testing results. www.faa.gov/about/initiatives/cabin_safety/portable_oxygen/ Date last accessed: March 7, 2017.

70 Akero A, Edvardsen A, Christensen CC, et al. COPD and air travel. Oxygen equipment and preflight titration of supplemental oxygen. Chest 2011; 140: 84-90. 
71 Fischer R, Wanka ER, Einhaeupl F, et al. Comparison of portable oxygen concentrators in a simulated airplane environment. Respir Med 2013; 107: 147-149.

72 IATA oxygen delivery system for adult passengers. www.iata.org/whatwedo/safety/health/Documents/guidelinesoxygen-delivery-passengers.pdf Date last accessed: March 7, 2018.

73 Sabit R, Thomas P, Shale DJ, et al. The effects of hypoxia on markers of coagulation and systemic inflammation in patients with COPD. Chest 2010; 138: 47-51.

74 Perez-Rodriguez E, Jimenez D, Diaz G, et al. Incidence of air travel-related pulmonary embolism at the MadridBarajas airport. Arch Intern Med 2003; 163: 2766-2770.

75 Scurr JH, Samuel SJ, Bailey-King S, et al. Frequency and prevention of symptomless deep vein thrombosis in long haul flights: a randomised trial. Lancet 2001; 357: 1485-1489. 